\title{
Article
}

\section{The Procedural Fairness Limitations of Fitness to Practise Hearings: a case study into social work}

Kirkham, R, Leigh, J, McLaughlin, K and Worsley, Aidan Richard clive Available at http://clok.uclan.ac.uk/24890/

Kirkham, R, Leigh, J, McLaughlin, $K$ and Worsley, Aidan Richard clive ORCID: 0000-0002-3925-3297 (2019) The Procedural Fairness Limitations of Fitness to Practise Hearings: a case study into social work. Legal Studies, 39 (2). pp. 339-357. ISSN 0261-3875

It is advisable to refer to the publisher's version if you intend to cite from the work. http://dx.doi.org/10.1017/lst.2018.42

For more information about UCLan's research in this area go to http://www.uclan.ac.uk/researchgroups/ and search for <name of research Group>.

For information about Research generally at UCLan please go to http://www.uclan.ac.uk/research/

All outputs in CLoK are protected by Intellectual Property Rights law, including Copyright law. Copyright, IPR and Moral Rights for the works on this site are retained by the individual authors and/or other copyright owners. Terms and conditions for use of this material are defined in the policies page.

\section{CLoK}

Central Lancashire online Knowledge www.clok.uclan.ac.uk

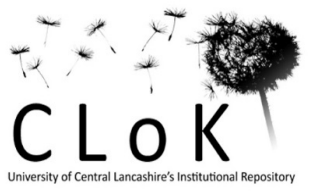




\title{
The Procedural Fairness Limitations of Fitness to Practise
}

\section{Hearings: a case study into social work}

\author{
Richard Kirkham, Jadwiga Leigh, Kenneth McLaughlin and Aidan Worsley* \\ University of Sheffield, University of Sheffield, Manchester Metropolitan University and University of Central \\ Lancashire
}

The norm in fitness to practise proceedings (FTPP) is that where sanctions might be imposed procedural fairness requires a court-like hearing. This article questions that paradigm, using empirical research to focus on the FTPP to which social workers must account. Procedural fairness is a multi-faceted legitimising concept used to justify the design of decision-making processes. With FTPPs, the major justification is an 'instrumentally' focused model of procedural fairness which prioritises making decisions that look right, a goal which is delivered in the context of social work. But other justifications for procedural fairness are inadequately fulfilled, with in particular a 'dignitarian' respect not achieved due to the high levels of non-attendance by registrant social workers. Further, procedural fairness as 'public accountability' is undermined due to the relative lack of engagement of FTPPs with the perspective of the social work community. These findings hint that in the context of a poorly organised and resource-poor profession other hybrid forms of FTPP might have a stronger claim to procedural fairness than the court-like model.

\section{INTRODUCTION}

In January 2018, the Conduct and Competence Committee ('the CCC') of the Health and Care Profession Council (HCPC) ruled that a social work manager had to be sanctioned after his decisions, coupled with a failure to record and carry out supervision sessions, left children at risk. The manager was made subject to a 12-month conditions of practice order despite the CCC conceding that he had worked with 'a heavy caseload, poor working conditions, inadequate

\footnotetext{
* The authors express their gratitude to the feedback they received from colleagues, in particular Joe Tomlinson and that provided by the referees.

* The authors express their gratitude to the feedback they received from colleagues, in particular Joe Tomlinson and that provided by the referees.
} 
management support of him in his role as a manager, and significant personal health issues'. The Committee heard that, at one stage, the manager had been responsible for 120 cases even though 65 cases was the optimum caseload. Two social workers from his team who gave evidence at the hearing said the manager had done all he could to ease the burden for the team. However, he was referred to the HCPC because as the manager he was responsible for ensuring cases progressed within his team.

Cases such as this are a common feature of professional regulation and raise delicate questions as to the extent to which it is reasonable to sanction individual professionals where system failings are a contributory factor. ${ }^{2}$ Such cases also challenge us to reflect upon the procedural fairness of the processes by which professionals are disciplined. As fitness to practise proceedings (FTPP) have power to bar professionals from practising, it is commonly assumed that a court-like forum is required to provide the requisite procedural fairness to oversee the process. This article questions whether that dominant paradigm is appropriate in all circumstances, with a particular focus on one profession, social work. It is supported by the results of two empirical studies into the work of the $\mathrm{HCPC}^{3}$ and a content analysis of the judicial appeals process that oversees its work.

Procedural fairness is a legitimising concept used to justify the design of decision-making processes, but the concept wraps together multiple underlying objectives. In this article, three discrete procedural fairness justifications - instrumental, dignitarian and public accountability

\footnotetext{
${ }^{1}$ L Stevenson 'Social worker sanctioned for supervision failures despite 'heavy caseload, poor working conditions' (3 January 2018) Community Care. http://www.communitycare.co.uk/2018/01/03/social-worker-sanctioned-supervision-failures-despite-heavycaseload-poor-working-conditions/ (Accessed 4 February, 2018).

${ }^{2}$ Eg see General Medical Council v Bawa-Garba [2018] EWHC 76 (Admin); D Cohen 'Back to blame: the BawaGarba case and the patient safety agenda' (2017) BMJ 359.

${ }^{3}$ See K McLaughlin, J Leigh and A Worsley 'The State of Regulation in England: From the General Social Care Council to the Health and Care Professions Council' (2016) 46(4) British Journal of Social Work 825; J Leigh, A Worsley and K McLaughlin 'An analysis of HCPC fitness to practise hearings: Fit to Practise or Fit for Purpose?' (2017) 11(4) Ethics and Social Welfare 382; A. Worsley, K. McLaughlin and J. Leigh 'A Subject of Concern: The experiences of social workers referred to the Health and Care Professions Council' (2017) 47 British Journal of Social Work 2421.
} 
- are used as a framework through which to scrutinise the FTPP as operated for social workers. These justifications are overlapping and competing, and the degree of emphasis to give each is the responsibility of policy-makers, but solutions should be reassessed through reflection on experience.

This article argues that the design of the social work FTPP is instrumental in focus, providing a redemption model of decision-making which tests a registrant's capacity to demonstrate contrition for investigated malpractice following an independent hearing. ${ }^{4}$ The FTPP design, however, pays considerably less attention to achieving either dignitarian respect for professionals or public accountability. For well-resourced professions, FTPPs create the space for these thicker justifications for procedural fairness to be realised, but in the context of the under-resourced social work profession the space is not filled. Instead, in practice the social work FTPP achieves low levels of participation by investigated registrants and a shortage of engagement with the perspective of the social work profession.

Even if the social work FTPP delivers upon its primary goal of protecting the public, therefore, its current design risks delivering a cosmetic justice system and thereby undermining wider regulatory goals, such as building trust amongst the social work community and learning from instances of malpractice. In response to this problem, the procedural fairness merits of one alternative model are considered. Through this alternative a more balanced disciplinary process could be designed, better equipped to offer practitioners the opportunity to receive due process and facilitate a stronger focus on institutional learning. The proposed approach depends upon an enhanced willingness to integrate the added potential of inquisitorial dispute resolution processes. The Government have partially moved towards this model in a recent consultation paper, ${ }^{5}$ but the focus remains weighted against the registrant.

\footnotetext{
${ }^{4}$ P Case 'The Good, the Bad and the Dishonest Doctor: The General Medical Council and the redemption model' of fitness to practise' (2011) 31 LS 591.

${ }^{5}$ Department of Education and Department of Health and Social Care Social Work England: Consultation on secondary legislative framework (London: TSO, 2018).
} 
In this article, the challenge of designing FTPPs is introduced in Part 2. In Part 3 the concept of procedural fairness, and the variable goals that are pursued within it, are developed. In Part 4 current operational practice is scrutinised before, in Part 5, the argument for an alternative approach is laid out.

\section{THE DESIGN OF FITNESS TO PRACTICE PROCEEDINGS}

\section{Fitness to practise proceedings, the HCPC and social workers}

The primary purpose of the regulation of professions is to provide public protection against practitioners that are unfit to practice,${ }^{6}$ a duty which is often stated in legislation. ${ }^{7}$ It is also a duty that has been confirmed in court, ${ }^{8}$ and is necessary both to protect members of the public and to provide users with confidence as to the competence and integrity of professionals. This duty has profound implications for professionals. As Sir Thomas Bingham MR once ruled: ' $[\mathrm{t}]$ he reputation of the profession is more important than the fortunes of any individual member. Membership of a profession brings many benefits, but that is part of the price. ${ }^{99}$

Public protection is achieved in part by safeguarding access into the professions but also through establishing FTPPs, which are designed to deal with allegations as to the fitness to practice of practitioners. In designing FTPPs, three broad design choices are on offer. One choice is to adopt a purely 'court-like' process where the emphasis is on formality and adjudication. Another option is to secure settlements through various forms of alternative

\footnotetext{
${ }^{6}$ Department for Health Promoting Professionalism, Reforming Regulation: A paper for consultation (London: TSO, 2017), 9.

${ }^{7}$ Eg Medical Act 1983, s 1(1A).

${ }^{8}$ Bolton v Law Society [1994] 1 WLR 512, at 517-519; Gupta v General Medical Council [2002] 1 WLR 1691 at [21]; Khan v General Pharmaceutical Council [2016] UKSC 64; [2017] 1 WLR 169 at [36].

${ }^{9}$ Ibid, Bolton at [519].
} 
dispute resolution short of adjudication. In between these alternatives, 'hybrid' or 'mixed'10 designs can be deployed to marry the benefits of 'court-like' and 'informal' models.

The history of professional regulation reveals a presumptive assumption in favour of a 'court-like' model of decision-making for FTPPs. For social workers, the relevant FTPP is operated by the HCPC, a lay regulator. ${ }^{11}$ Referrals of fitness to practise matters can be made by a range of sources, including members of the public, employers, the police, other registrants and self-referrals. As with many court-like processes, there are some informal features of the model, such as early filtering opportunities through which decisions can be made about 'weak' allegations. In the HCPC model, there is also a capacity to pursue a mediated settlement, ${ }^{12}$ although it has not been the policy of the HCPC to use this option. ${ }^{13}$ Instead, once a preliminary screening process has been completed a formal investigative process is commenced.

Following an investigation, the initial findings are reported to a separate Investigation Committee which decides how to proceed. ${ }^{14}$ If the Investigation Committee decides that there is a case to answer, the HCPC instigate proceedings for the case to be heard at a formal hearing of the CCC, comprised of a registrant from the same profession as the person being investigated, a lay person who is not registered with the HCPC and a chair (who may be a lay person or a HCPC registrant from any regulated profession). ${ }^{15}$ Subject to confidentiality requirements, hearings are open to the public and the press, with the CCC's decisions and the reasons for them provided in public.

\footnotetext{
${ }^{10}$ Eg L Fuller 'The Forms and Limits of Adjudication' (1978) 92 Harvard Law Review 353, 405-409.

${ }^{11}$ National Health Service Reform and Health Care Professions Act 2002. Health and Social Work Profession Order 2001 [2002 S.I. No.254] (as amended), enacted under section 60 of the Health Act 1999. Under the Children and Social Work Act 2017 s 44, the housing of the FTPP process is currently under review, see Department of Education and Department of Health and Social Care, above $n 7$.

${ }^{12}$ Health and Social Work Profession Order 2001, arts 23 and 24.

13 See HCPC Practice Note: Mediation. (August 2012), available at http://www.hcpcuk.org/assets/documents/10001DDCPRACTICE_NOTE_Mediation.pdf (accessed 18 February 2018); Ireland \& Anor v Health and Care Professions Council [2015] EWHC 846 (Admin), at [28].

${ }^{14}$ Health and Social Work Profession Order 2001, art 26.

15 Ibid, art 27.
} 
The focus in CCC hearings is on establishing whether an individual registrant's 'fitness to practise is impaired' by reason of one of a selection of pre-defined grounds. ${ }^{16}$ The standard of proof is a balance of probabilities test, ${ }^{17}$ not as formerly one of beyond reasonable doubt. ${ }^{18}$ If the panel finds the case is well-founded, there are a range of actions it can make including: cautions, setting conditions of practice, suspension, or striking the registrant from the Register. ${ }^{19}$ Following the decision, the registrant has the option to appeal the decision and/or sanction to the High Court.

Overall, therefore, the emphasis of the FTPP operated for social workers is on a highly 'court-like' model of dispute resolution.

\section{The regulatory environment of social workers}

The design choice for any dispute resolution process is not dictated by theoretical or legal prescription, but by the politics and the context in which it operates. The context in which FTPPs have evolved is wrapped up in the long history of the regulation of professionals, and a gradual shift from self-regulation to external regulatory models. In medicine $\mathrm{e}^{20}$ and $\mathrm{law}^{21}$ for instance, self-regulation was fomerly accepted because the professions possessed reputational incentives to maintain high standards, together with the relevant expertise and technical knowledge to construct suitable standards, and administer disciplinary hearings for breaches of those standards. ${ }^{22}$ In recent decades, however, as the public sector has expanded its reliance on

\footnotetext{
${ }^{16}$ Ibid, art 22

${ }^{17}$ Health and Social Care Act 2008, s 112.

${ }^{18}$ Health Act 1999, s 60A.

${ }^{19}$ Health and Social Work Profession Order 2001, art 29(5).

${ }^{20}$ Eg M Davies 'The Future of Medical Self-regulation in the UK: Renegotiating the State-Profession Bargain?' (2015) 14 Medical Law International 236.

${ }^{21}$ See N O'Brien and M Seniveratne Ombudsmen at the Crossroads: The Legal Services Ombudsman, Dispute Resolution and Democratic Accountability (London: Palgrave MacMillan, 2017).

${ }^{22}$ Eg A Ogus 'Rethinking self-regulation' (1995) 15(1) Oxford Journal of Legal Studies, 97.
} 
professionals, the Government has come under pressure to impose external regulation to protect users from poor performance. ${ }^{23}$

External regulation now covers the activity of a wide array of health and care professionals, ${ }^{24}$ transposing across to non-medical healthcare professionals, ${ }^{25}$ including social workers. From the seventies onwards, a series of major incidents raised extensive political, media and public concerns about the social work profession. ${ }^{26}$ Like other countries, government policy responded by moving towards a system of social work registers, ${ }^{27}$ with a common objective the importance of enhancing public confidence in social work services. ${ }^{28}$ In 2010 , the responsibility for regulating social workers was transferred from a bespoke social work body, the General Social Care Council, to an umbrella lay regulator for 16 separate 'allied health professions', the HCPC. $^{29}$

In the social work sector, the lay solution resulted in a regulator which was not affiliated with or experienced in the practice that it regulates. This dynamic created a regulatory challenge of establishing decision-making processes which are sufficiently cogniscant of the technicality of the regulated activity and capable of refining the relevant professional standards to the shifting professional and regulatory environment. ${ }^{30}$ To add to the challenge, key differences distinguish social work from other sectors and place the profession in a weaker position. These include the comparatively underdeveloped process for setting standards of good practice and

\footnotetext{
${ }^{23}$ Eg D Schon 'The crisis of professional knowledge and the pursuit of an epistemology of practice' in J. Raven and J. Stephenson (eds), Competence in the Learning Society (New York: Peter Lang, 2001).

${ }^{24}$ Eg Care Standards Act 2000.

${ }^{25}$ Department for Health, The Regulation of Non-Medical Healthcare Professionals (London: TSO, 2006).

${ }^{26} \mathrm{Eg}$ L Blom-Cooper A Child in Trust: The Report of the Panel of Enquiry Into the Circumstances Surrounding the Death of Jasmine Beckford (Wembley, Middlesex: London Borough of Brent, 1985); Lord Laming The Victoria Climbié Inquiry Cm 5730 (London: TSO, 2003).

${ }^{27}$ G Kirwan, and B Melaugh 'Taking Care: Criticality and Reflexivity in the Context of Social Work Registration'. (2015) 45 British Journal of Social Work 1050.

${ }^{28}$ K Healy '2015 Norma Parker Address: Being a Self- regulating Profession in the 21st Century: Problems and Prospects.' (2016) 69 Australian Social Worker 1.

${ }^{29}$ National Health Service Reform and Health Care Professions Act 2002. Health and Social Work Profession Order 2001 [2002 S.I. No.254] (as amended), enacted under section 60 of the Health Act 1999.

${ }^{30} \mathrm{~J}$ Haney Regulation in Action (London: Karnac Books, 2012).
} 
the lack of a well embedded representative body to inform the construction of those standards. ${ }^{31}$ Little has been done to build the profession in contrast to other sectors where collective organization and a commitment to improving standards is strong. ${ }^{32}$

Under the existing HCPC lay regulator model, where fitness to practise issues arise one result has been a narrowing focus on the conduct of individual professionals rather than organisational issues. This focus has raised concerns that there has been a reluctance to examine fully the institutional issues that might be thought to generate the conditions for malpractice or to consider what complaints tells us about 'the role and responsibility of the professional in question' ${ }^{33}$ Partly in response to such concerns, under the Child and Family Social Work Act 2017 a bespoke regulator for social work is to be introduced. ${ }^{34}$ This raises afresh the question of how best to deal with fitness to practise matters.

\section{A FRAMEWORK FOR CONCEPTUALISING PROCEDURAL FAIRNESS}

\section{Three underpinning elements to procedural fairness}

This article analyses FTPPs through the lens of procedural fairness because the dominant reason for their current court-like model is that they offer the most procedurally fair solution for the public and for all individuals involved in the process. That procedural fairness is the embedded

\footnotetext{
31 The British Association of Social Workers (BASW) was formed in 1970 by amalgamating disparate representative groups, but it has only recently (October 2011) established Trade Union functions to enable representation at disciplinary tribunal.

${ }^{32}$ Even in the proposals for the introduction of a new regulator, Social Work England, whilst the pursuit of quality is part of new body's remit, its primary concern is with 'threshold' standards rather than 'quality' standards.

${ }^{33}$ Leigh et al, $\mathrm{n} 3$ above.

${ }^{34} \mathrm{~S}$ 36. This body will be called Social Work England, see Department of Education and Department of Health and Social Care, n 5 above.
} 
rationale for FTPPs is supported by numerous government statements and judicial pronouncements. ${ }^{35}$

The importance of procedural fairness in decision-making has a rich jurisprudential heritage but its detail remains highly contestable both in theory and law, and is context dependent on the goals, principles and values of the decision-making system involved. ${ }^{36}$ However, although the literature on procedural fairness does not provide a single agreed definition, three overlapping discrete elements of the concept stand out. These elements provide a 'grammar' of procedural fairness through which to understand the institutional design choices available, with each element implying that subtly different features should be incorporated into a decision-making process. They also provide useful benchmarks through which to interrogate the qualities of an individual decision-making process. ${ }^{37}$

The first element focuses on a process's instrumental capacity to deliver substantive justice, namely the correct outcome. This is the element of fairness most directly connected to the social good that a decision-making process is designed to deliver and is arguably the most important driver behind procedural design. ${ }^{38}$ Procedural fairness requires that the potential for arbitrary discretion and bias is reduced by using procedure to force the decision maker to adhere to the purpose and values for which the decision-making power was created. In the context of FTPPs, this entails that the goal of public protection is safeguarded through processes that guarantee an independent rigorous investigation and hearing of alleged breaches of standards. To achieve the correct decision, participation of affected individuals is only necessary to the extent needed to

\footnotetext{
${ }^{35}$ Eg Department of Health, Regulation of Health Care Professionals. Regulation of Social Care Professionals in England. Cm.8995 (London: TSO, 2015), at para 5.7.

${ }^{36}$ Eg Lloyd v McMahon [1987] 625, at xx per Lord Bridge; $R v$ Home Secretary ex $p$ Doody [1994] 1 AC 531.

${ }^{37}$ Eg D Hovell The Power of Due Process: The Value of Due Process in Security Council Sanctions DecisionMaking. (Oxford: OUP, 2016).

${ }^{38}$ D Galligan Due Process and Fair Procedures (Oxford: Oxford University Press, 1996).
} 
garner a more complete understanding or to assist in the proper interrogation of different interpretations of fact and may be outweighed by the costs. ${ }^{39}$

A second element is a dignitarian one which emphasises the inherent value in respecting the interests of the autonomous individual. ${ }^{40}$ Thus the importance of procedural fairness here is rooted in the value for the individual of being involved in the process and recognised as capable of asserting 'their interests and preferences'. ${ }^{41}$ A proportionate level of participation makes it more likely that the participant will recognise the justice of the outcome and the legitimacy of the decision-making authority, as well as securing closure for all involved. ${ }^{42}$ The dignitarian focus, therefore, addresses the potential for a purely instrumentally designed process either to ignore the benefits of participation or, more likely, to acknowledge participation formally to some degree, but in practice operate to hinder opportunities for meaningful participation.

A third element, public accountability, raises more challenging questions of a decisionmaking process. This element highlights the public interest in designing systems that are seen to be legitimate by a wider body of interests than those recognised by majoritarian rule alone, in particular those interests most closely involved in and impacted by the process. Transparency aids public accountability but is not sufficient, as there is always a risk that processes become too rigid and one-dimensional in their outlook. Therefore, rather than assuming that the values integrated into the decision-making process system are correct, procedural fairness can facilitate a broader ongoing re-evaluation, adaptation and reconfirmation of those values. ${ }^{43}$ Thus, the respect of the regulated sector for decision-making authority is not merely imposed, but nurtured through the indirect participation of the community affected by decisions. ${ }^{44}$

\footnotetext{
${ }^{39}$ Ibid, 70.

${ }^{40}$ Eg J Mashaw Due Process in the Administrative State (New Haven: Yale University Press, 1985), 104-55.

${ }^{41}$ Hovell, $\mathrm{n} 37$ above, 76.

${ }^{42}$ M Korsgaard, D Schweiger and H Sapenza 'Building commitment, attachment, and trust in strategic decisionmaking teams: The role of procedural justice’ (1995) 38 Academy of Management Journal 60, 68.

${ }^{43}$ P Rosanvallon Democratic Legitimacy: Impartiality, Reflexivity, Proximity (Princeton, NJ: Princeton University Press, 2011); T.R.S. Allan, 'Procedural Fairness and the Duty of Respect' (1998) OJLS 497, 510.

${ }^{44}$ Hovell, n 37 above, 7.
} 


\section{Thin and thick conceptions of procedural fairness}

The varying elements that underpin procedural fairness are not mutually exclusive and can coexist but in institutional design there is a choice to be made as to the emphasis to give them. Further, as there is no one test of procedural fairness available to measure the quality of a decision-making process, choices are ultimately rooted more in pragmatism than principle. Such choices are aimed at finding the right balance, and are policy-based and competitive. ${ }^{45}$ The greater the political demand for one element of procedural fairness, the less will be the influence of the others. ${ }^{46}$ However, because all solutions will experience imperfections, institutional design is an ongoing process which responds 'to the condition of the community', ${ }^{47}$ with 'fine-tuning' on the basis of experience inevitable ${ }^{48}$ in order to reflect more accurately the underlying social ends and goals being pursued. For instance, the growth of alternative dispute resolution (ADR) in consumer law ${ }^{49}$ is an example of a former understanding of what procedural fairness amounts to, embedded in the instrumental value of court-based processes to provide justice, giving way to a new approach considered more capable of accommodating additional political goals. Thus ADR is seen as an effective way to enhance the dignitarian element of procedural fairness by widening real access to justice, as well as to improve the public accountability element of procedural fairness by providing for an efficient mass dispute resolution system. ${ }^{50}$

\footnotetext{
45 J Mashaw Bureaucratic Justice: Managing Social Security Disability Claims. (New Haven and London: Yale University Press, 1983), xx.

${ }^{46}$ Ibid, 24; M Adler 'A Socio-legal Approach to Administrative Justice' (2003) 25(4) Law \& Policy 323.

${ }^{47}$ Galligan, $\mathrm{n} 38$ above, 15.

${ }^{48}$ Eg G Gee and G Weber, 'Rationalism in Public Law' (2013) 76 MLR 708.

${ }^{49}$ Eg P Cortes (ed.), The New Regulatory Framework for Consumer Dispute Resolution. (Oxford: Oxford University Press, 2016).

${ }^{50}$ M Cappelletti, 'Alternative Dispute Resolution Processes within the Framework of the World-Wide Access-to Justice Movement' (1993) 56 MLR 282.
} 
The consumer law example also illustrates that in design, what might be termed 'thin' and 'thick' models of procedural fairness are available. Thin accounts of procedural fairness will tend to focus on what is formally necessary for lawful public authority, as determined in a topdown fashion by parliamentary, executive or judicial authority. Such solutions would typically defer considerable discretionary power to public decision-makers, are built primarily around instrumental accounts of procedural fairness and only nominally provide for dignitarian and public accountability elements. By contrast, thicker accounts of procedural fairness will look to secure a source of authority which includes but goes beyond formal top-down coercive power. Such solutions will typically be more committed to decision-making systems that integrate within them effective opportunity for dignitarian and public accountability elements to be fulfilled. The thicker goal here is to secure a genuine perception of justice amongst those directly impacted by decision-making processes and the regulated communities involved.

When choosing the balance between thin and thick models of procedural fairness, with decision-making processes there is a constant need for regular reflection based upon experience, with solutions dictated by what is necessary to legitimise a decision-making process. In other words, what drives shifts and redesigns to a decision-making process is the need to maintain qualities 'that provide arguments for the acceptability of its decisions'. ${ }^{51}$ This adjustable concept of acceptability, or legitimacy, provides a bridge to understand the gap between normative claims to procedural fairness and the practice of institutional design. Legitimacy is a measure of the degree of support a body enjoys for its work, and the level of influence and power leverage it can exert on other bodies and individuals. ${ }^{52}$

With this in mind, likely scenarios can be anticipated in which different designs will be effective, or ineffective, in enhancing the goals and legitimacy of the decision-making process

\footnotetext{
${ }^{51}$ Mashaw, n 45 above, 24.

${ }^{52}$ Eg D Beetham The Legitimation of Power (London: Macmillan, 1991); D Easton A framework for political analysis (Englewood Cliffs: Prentice-Hall, 1965).
} 
in question. For instance, the 'court-like' process of the FTPP has a clear instrumental purpose of delivering the collective interest in public protection against practitioners who have breached professional standards. Further, the long heritage of disciplinary panels being used to manage fitness to practise matters implies that it has been successful in securing public acceptance. Notwithstanding this heritage, indicators that a decision-making process built on this model was under-performing might include a wider loss of faith in the sector being regulated, or evidence of incorrectly decided decisions.

The integrity of the rule of law includes an acceptance that various participatory rights are included in FTPPs to ensure dignitarian respect for the interests of impacted individuals. ${ }^{53}$ Indications that a respect for the interests of individuals is not being fully delivered, however, might include significant levels of lasting discontent post decision and, amongst registrants, a loss of faith or refusal to engage during the decision-making process itself.

Public accountability elements for procedural fairness might be thought to be sufficiently built into the court-like model through its public nature, with the values of the system well detailed in the law and practice of the decision-making process and the availability of an appeal route. With FTPPs, the public interest risk that they are insufficiently rigorous and allow weak practitioners to continue their trade and endanger the public ${ }^{54}$ is guarded against by the oversight role of the 'regulator's regulator', the Professional Standards Authority. ${ }^{55}$ However, there are other public interests that might not be well served by existing processes. For instance, the process might be too punitive on the individual practitioner, or the morale of the regulated profession might become so undermined by the process that resource strains are indirectly placed on providers through recruitment shortages, staff absences and localised walk-outs. A

\footnotetext{
${ }^{53}$ Osborn v Parole Board [2014] AC 1115.

${ }^{54}$ Eg J Chamberlain 'Malpractice, Criminality and Medical Regulation: Reforming the Role of the GMC in Fitness to Practice Panels', (2016) Medical Law Review 497.

55 The Professional Standards Authority has power to bring appeals against decisions of FTPPs if it views them as too lenient. It also has a place on the Advisory Board for Social Work England.

https://www.professionalstandards.org.uk/home
} 
further risk is that the decision-making process is resource inefficient. Such inefficiency might simply relate to the financial and time cost in delivering the process, but there might also be a failure to maximise the reflective learning opportunities that any decision-making process creates. In the dispute resolution literature there is a wealth of literature on the knowledge-rich potential of complaints. ${ }^{56}$ Thus although any one complaint might be associated with a single complainant, it is often the case that the grievance can tell us something organisationally useful about its causes that can assist in preventing similar instances occurring. Indicators that a process is not satisfactorily delivering might include organised campaigns against the decisionmaking process, government plans for reform, or loss of morale in the sector.

\section{SOCIAL WORKERS: A CASE STUDY INTO PROCEDURAL FAIRNESS}

\section{Methods of inquiry}

To gain a picture of the procedural fairness of FTPPs used to consider referrals against registered social workers (hereafter registrants), this paper is based upon a mixed methods study. In doing so, the paper draws upon published material and research on the HCPC and the findings of three discrete small scale empirical studies.

In the first, the 'Interview' study, semi-structured interviews were held with eight qualified social workers, all of whom had been subject to the HCPC process for professional misconduct. ${ }^{57}$ Participants were chosen whose outcomes reflected the proportion of outcomes

\footnotetext{
${ }^{56}$ Eg R Thomas 'Administrative Justice, Better Decisions, and Organisational Learning' (2015) Public Law 111.

${ }^{57}$ Full details of the research can be found in Worsley et al, $\mathrm{n} 3$ above.
} 
of all cases. ${ }^{58}$ The interviews were designed to understand the underlying dynamics, motivations and experiences behind the actions of social workers subject to professional misconduct hearings. ${ }^{59}$

In the second, a 'Case Review' study was undertaken of the publicly available notes of 34 fitness to practise hearings of HCPC cases involving social workers from August 2012 to 31 December 2014. The sample was selected to choose only cases in which individual practice concerns were at issue as opposed to personal character (eg caused by allegations of abuse of drugs or alcohol, or allegations of fraud or crime). ${ }^{60}$ Practice concerns were focused on because they were more likely to raise wider sector specific concerns about the organisational expectations of social workers. Cases were coded using a content/thematic analysis in which themes identified for coding were selected primarily based on recurrence, pattern and relationship. ${ }^{61}$

In the third study, to understand the depth of procedural fairness required by the law a content analysis was undertaken of the case law of all reported appeals against decisions of the HCPC, and its predecessor the Health Professions Council, up until January 2018.

The combination of these studies is qualitative, not quantitative. In other words, the samples reviewed are too small to draw definitive conclusions, but alongside the available evidence elsewhere the evidence uncovered does raise significant concerns as to the long-term viability of the FTPP as applied to social workers in its current form.

\footnotetext{
${ }^{58}$ Of the eight social workers, interviewed three were found to have No case to answer/No further action, a further three received either a caution/warning/or conditions of practice, and two were struck off the HCPC register. By way of comparison, the HCPC figures show that of the 155 cases where social workers were taken before a FTP hearing that year ( $1^{\text {st }}$ April 2014-31 ${ }^{\text {st }}$ March 2015) approximately 25\% received a caution or conditions of practice, $32 \%$ had no further action/no case to answer and $43 \%$ were either struck off or suspended, HCPC Annual Fitness to Practice report (London: TSO, 2015).

${ }^{59} \mathrm{P}$ Beresford 'The role of service user research in generating knowledge-based health and social care: from conflict to contribution' (2007) 3(3) Evidence and Policy 329.

${ }^{60}$ Leigh et al., n 3 above.

${ }^{61}$ V Braun and V Clarke 'Using thematic analysis in Psychology' (2006) 3 Qualitative Research in Psychology 77; M Carey Qualitative Research Skills for Social Work (Farnham: Ashgate, 2012).
} 


\section{Delivering Instrumental Goals}

FTPPs are primarily legitimised on the basis that they deliver the instrumental element of procedural fairness. This entails that the process achieves clear decisions through a publicly transparent process within which complaints against registrants are tested objectively by an independent investigator and then a separate independent panel.

The HCPC is responsible for 350,330 registrants, almost half of whom are social workers in England. ${ }^{62}$ Dealing with complaints currently accounts for almost half of the HCPC's overall expenditure, and costs have risen consistently in recent years. ${ }^{63}$ Of those complaints, most $(54 \%)$ involve social workers, ${ }^{64}$ and individual social workers are proportionally more likely to be referred than other professionals (1.33\% in 2016/17), with the only other profession near the same level being paramedics $(1.23 \%) .{ }^{65}$ This pattern might be explainable by the nature of social work, which is often contentious in terms of the social worker's need to navigate the boundaries between public and private life, and deal with highly sensitive issues. ${ }^{66}$ This ongoing potential for public criticism is reflected in the scale of complaints coming from the public (62.6\%), more than any other profession.

Many of these referrals are filtered out before full investigation, but a significant number (approximately 200 social work cases per annum) still get passed on by the Investigation Committee to the CCC for a full hearing. ${ }^{67}$ Once at the CCC, for the period $2012-17,72 \%$ of cases led to some form of sanction against the registrant. ${ }^{68}$ By themselves, these statistics tell us nothing about the quality of the decisions being made in terms of their correctness, but two

\footnotetext{
${ }^{62}$ HCPC Fitness to Practise, Annual Report 2016/17 (London: TSO, 2017), 11.

${ }^{63}$ HCPC Annual Report: Key Financial Information 2016/17 (London: HCPC, 2017), 8-9.

${ }^{64}$ HCPC, n 62 above, 14.

65 Ibid, 16.

${ }^{66}$ G Bisell Organisational Behaviour for Social Work (Bristol: Policy Press, 2012).

${ }^{67} \mathrm{HCPC}, \mathrm{n} 62$ above, 42.

${ }^{68}$ According to the HCPC reports over the 2012-17 period there were 1522 decisions of which 1121 resulted in some form of sanction, HCPC Annual Fitness to Practise: Key Information Reports, 2013-2017. Available at: http://www.hcpc-uk.org/publications/reports/index.asp?id=710 (accessed 18 February 2018)
} 
themes stand out from the research, which inform the nature of the instrumental procedural fairness provided.

The appeals process guarantees the process not the outcome

Although the FTPP allows for an appeal to the High Court, this is a limited and costly form of safeguard against incorrect decisions. According to the HCPC's annual reports, through 201217, compared to the 1121 cases that resulted in a sanction, only 21 were appealed, with six of these cases withdrawn or refused before hearing and only five leading to the case being remitted back to the HCPC for reconsideration. ${ }^{69}$ In one of those remitted cases the original decision was then remade by a fresh panel and subsequently unsuccessfully appealed. ${ }^{70}$ In the others the sanction was reconsidered. ${ }^{71}$

The rare use of the appeals process and its low success rate for registrants might indicate the robustness of the initial decision-making process, but there are good reasons for not drawing this as a necessary conclusion. In processing appeals against the HCPC, the courts operate a restricted mandate, as with other existing disciplinary routes such as that operated by the General Medical Council. ${ }^{72}$ One aspect of this approach is that an appeal to the court does not involve a re-hearing of the evidence. ${ }^{73}$ The focus is instead on establishing whether the original

\footnotetext{
${ }^{69}$ Not all of these cases are available online, but published cases in the equivalent period include: Clery $v$ HCPC [2014] EWHC 951 (Admin); Levett v Health And Care Professions Council [2015] EWCA Civ 580 (plus preceding HC case); Goodwin v Health and Care Professions Council [2014] EWHC 1897 (Admin); Ireland \& Anor $v$ Health and Care Professions Council [2015] EWHC 846 (Admin); Leeks v Health and Care Professions Council [2016] EWHC 826 (Admin); Chigoya v Health and Care Professions Council [2015] EWHC 1109 (Admin); David v Health and Care Professions Council [2014] EWHC 4657 (Admin); David v Health and Care Professions Council [2015] EWHC 4082 (Admin); Falodi v Health and Care Professions Council [2016] EWHC 328 (Admin); Davies v HCPC [2016] EWHC 1593 (Admin); Redmond v Health and Care Professions Council [2016] EWHC 2490 (Admin); Estephane v Health And Care Professions Council [2017] EWHC 2146 (Admin); McDermott v HCPC [2017] EWHC 2899 (Admin).

${ }^{70}$ David, $\mathrm{n} 69$ above.

${ }^{71}$ Additionally, in McDermott, n 69 above, the court replaced a suspension order with a conditions of practice order.

${ }^{72}$ Falodi, n 69 above; Lindblom J in Rice v Health Professions Council [2011] EWHC 1649 (Admin) at [11] to [17].

${ }^{73}$ Fish v GMC [2012] EWHC 1269 (admin) at [28] and Redmond, n 69 above at [7-8], HHJ David Cooke.
} 
decision is manifestly wrong or there exists a serious procedural or other irregularity. In considering appeals, considerable deference is given to the specialist nature of the disciplinary panel. ${ }^{74}$ A review of the grounds that have been used to quash decisions of the HCPC and its predecessor reveals that the court has largely declined multiple legal arguments to critique the processes adopted by the CCC. ${ }^{75}$ Occasionally the court has picked holes in the quality of the reasons or evidence used by the CCC to justify its decisions ${ }^{76}$ and found that sanctions have been disproportionate to the finding. ${ }^{77}$ However, even where an appeal is upheld, the case is ordinarily remitted back to the original decision-maker for a rehearing.

The court in the appeal process, therefore, operates as a high level form of quality control and does not focus on the quality of the outcomes generated, other than to test for perverse or badly reasoned decisions. An indication that the courts recognise their limitations can be seen in two cases ${ }^{78}$ in both of which the judge, in some apparent sympathy with the registrant concerned, specifically advised the appellant to pursue the HCPC's internal review process. ${ }^{79}$

\section{The emphasis on credibility, remorse and insight}

The limits to the practical impact of the appeals process places a strong onus on the CCC to guarantee the correct outcome. A common theme in FTPPs across professions, however, is the emphasis placed upon the credibility of the registrant and their capacity to demonstrate remorse and insight. ${ }^{80}$ This pattern was repeated in the 'Case Review' study conducted for this paper, ${ }^{81}$

\footnotetext{
${ }^{74}$ CPR 52.11.3 and Ghosh v General Medical Council [2001] 1 WLR 1915, 1923, at [34], Lord Millett.

75 An exception is Reyburn v The Health Professions Council [2008] EWHC 476 (Admin) (Failure to hear the oral evidence of key witnesses).

${ }^{76}$ Ryell v Health Professions Council [2005] EWHC 2797 (Admin); Brennan v Health Professions Council [2011] EWHC 41 (Admin); Levinge v Health Professions Council [2012] EWHC 135 (Admin) (insufficient evidence to ground decision); David, n 69 above (applied the wrong test for dishonesty).

${ }^{77}$ Howlett, $R$ (on the application of) v Health Professions Council [2009] EWHC 3617 (Admin); Levinge n 76 above; McDermott, n 69 above.

${ }^{78}$ Azam, $R$ (on the application of) $v$ Health Professions Council [2005] EWHC 1129 (Admin); Muscat v Health Professions Council [2009] EWCA Civ 1090.

${ }^{79}$ A process required by Article 30(7) 2001 Order.

${ }^{80}$ Case, see $n 4$ above.

${ }^{81}$ For details see, Leigh et al. n 3 above.
} 
which revealed a tendency for decisions to be in part based upon an assessment of the credibility of the witness. For instance, in 14 out of 21 cases in which the registrant was struck off, their credibility was mentioned as being a deciding factor ${ }^{82}$ even though the registrant did not attend the hearing and reliance was placed instead on earlier submissions made by the registrant (eg at a disciplinary hearing or at the investigation stage). ${ }^{83}$ The study also found some evidence that the capacity to show remorse and insight is significant. In particular, in each of the three cases in which 'no further action' was applied, some form of acceptance of their error on the part of the registrant was demonstrated. Additionally, where sanctions were applied short of 'striking off' an ability to demonstrate insight into the errors of their practice was also a common theme. ${ }^{84}$

A further risk with FTPPs is that the search for truth is deprioritised in favour of obtaining acknowledgment of error on the part of the registrant. ${ }^{85}$ Evidence of the importance of attendance in social work FTPPs can be garnered from the underlying facts at issue in the cases which were reviewed in the 'Case Review' study. In the study, examples were found of a registrant being struck off, where the allegation that was being considered was less serious or equivalent to some of the cases in which registrants who received lesser penalties such as 'conditions of practice' or a 'caution'. For example, with the case of ' $\mathrm{H}$ '86 the allegations spanned three pages and included poor communication, insufficient record and time keeping, not meeting service users and making inappropriate comments. Notwithstanding the seriousness of the matters being dealt with, the registrant was able to show "some insight" into his "failings" by expressing his "genuine regret" for them. It was felt by the Panel that his fitness to practise was not currently impaired and he was thus given a caution. This compares with a

\footnotetext{
82 Ibid, 388 .

${ }^{83}$ Ibid

${ }^{84}$ Ibid, 391-4.

${ }^{85}$ Case, see $n 4$ above, 611.

${ }^{86}$ Ibid, 391.
} 
similar case of ' $\mathrm{C}$ ' who did not attend but who was struck off for not keeping up to date on case records. ${ }^{87}$

Any decision-making process is going to be prone to inconsistency but other studies have suggested that defining and measuring suitable conduct for social workers is problematic. ${ }^{88}$ The concern is that the ability of a registrant to attend his/her hearing has a strong influence on the outcome and the sanction, possibly more than the perceived seriousness of a registrant's misconduct or competence. ${ }^{89}$

\section{The Dignitarian Model}

To achieve procedural fairness in dignitarian terms the individual affected must have the opportunity to participate in the process. Under FTPPs, the registrant is directly involved at the investigation stage and has a right of attendance at the hearing itself. Non-attendance is unlikely to be a ground for review ${ }^{90}$ and according to the Scheme's rules cases can proceed without the registrant present if it is satisfied that notice has been duly served and it is just to do so.

\begin{tabular}{|l|c|c|}
\hline & Sanction & No Sanction \\
\hline Represented & 57 & 43 \\
\hline Attend without representation & 65 & 35 \\
\hline Non-attendance & 89 & 11 \\
\hline
\end{tabular}

Table A: Outcomes in percentages at the CCC depending on attendance and representation $(201 \mathrm{x}-2017)^{91}$

\footnotetext{
${ }^{87}$ Ibid, 389.

${ }^{88}$ F Wiles 'Blurring Private-Professional Boundaries: Does it Matter? Issues in Researching Social Work Students' Perceptions About Regulation.' (2011) 5(1) Ethics and Social Welfare 36.

${ }^{89} \mathrm{~K}$ McLaughlin, 'The Social Worker Versus the General Social Care Council: An Analysis of Care Standards Tribunal Hearings and Decisions' (2010) 40(1) British Journal of Social Work 311, 314.

${ }^{90}$ Azam v Health Professions Council [2005] EWHC 1129 (Admin).

${ }^{91}$ Data taken from the annual reports of the HCPC.
} 
Non-attendance occurs in almost half of all cases that end in a hearing, ${ }^{92}$ despite the manifest advantages in attending. Table A is based on the annual reports of the HCPC and details that when a registrant attends a hearing they are cleared in three times more cases than when they do not attend. The same data indicates that being represented at the hearing further increases a registrant's likelihood of success. This finding was reflected in the 'Case Review' study ${ }^{93}$ in which of the 21 cases that resulted in the strongest sanction, namely the registrant being 'struck off', in none was the registrant present or represented at the hearing. By contrast, of those nine registrants that were given lesser penalties, namely cautions or conditions, seven attended the hearing. In the four cases that were concluded with a ruling that no further action should be taken, the lightest of sanctions, all registrants attended. ${ }^{94}$

The finding that there is a correlation between attendance and outcome is neither surprising or new, and mirrors equivalent studies on FTPPs. ${ }^{95}$ Nor does it necessarily indicate that there is a problem. It might be that the low levels of attendance reflect a self-recognition of the registrant's misconduct or that the participatory input of the registrant at earlier stages in the process suffices to fulfil expectations of procedural fairness.

The research suggests, however, that there are more likely explanations for both nonattendance and non-representation. From the 'Interview' study the cost of legal fees was a commonly cited reason by participants for not being represented and those participants that did employ lawyers paid between $£ 5000$ - $£ 15,000$ in legal fees. ${ }^{96}$ The prospect of additional legal fees, and costs orders, at the appeal stage provide a further intimidatory element to the process. ${ }^{97}$ Further, because most hearings are held in London, travel costs are expensive for those living outside the south-east. Other practical factors likely to discourage attendance include the length

\footnotetext{
${ }^{92}$ HCPC, n 62 above, 44.

${ }^{93}$ Leigh et al, n 3 above.

${ }^{94}$ Ibid.

${ }^{95}$ McLaughlin, n 89 above.

96 Worsley et al n 3 above, 2429.

${ }^{97}$ See for instance, David, n 69 above where the legal cost order imposed on the appellant was $£ 10,000$.
} 
of proceedings, sometimes taking several days and overrunning, with witnesses being told they need to return the following day. Such circumstances incur substantial additional costs in terms of lost wages, hotel, transport and meal costs, as well as personal difficulties in terms of familial and/or other responsibilities. ${ }^{98}$ In combination, the drawn out process of the FTPP procedure, and the legal costs, resulted in three out of eight of the participants in the 'Interview' study withdrawing their engagement in the process. ${ }^{99}$

The lack of legal representation and the consistent non-attendance of registrants suggests that in many instances the HCPC fails to establish a clear voice for the accused registrant in FTPPs, one that it is unlikely to be fully replaced by the use of written evidence given the strong evidence that attendance does influence outcomes. The 'Interview' study also found that information-provision was weak and the level of support offered and available to registrants low. Notwithstanding the formal material made available by the HCPC, the 'Interview' study found that without legal support registrants were left under-informed of the process that they were entering into, in some cases not even knowing why a referral had been made. Alongside the prohibitive financial costs of obtaining legal support, other cultural and empirical factors help explain the disproportionality of the process. In particular, unlike in other professions, for social workers there is a relatively low influence of the trade unions or organised professional support for registrants, nor is there an embedded practice of insured support. This minimally effective support structure distinguishes social workers from many other more well-paid professions, from which the dominant court-like model of the FTPP has derived.

To add to the stress of the process, as with other FTPPs, ${ }^{100}$ registrants often have to wait significant periods of time for their case to be heard. ${ }^{101}$ The HCPC statistics evidence that an

\footnotetext{
${ }^{98}$ Worsley et al. n 3 above, 2429-2431.

${ }^{99}$ Ibid.

100 GMC Annual Report and Accounts 2013 ().

${ }^{101}$ Research works Public Response to Alternatives to Final Panel Hearings in Fitness to Practise Complaints (St Albans: Research Works, 2013) available at https://www.professionalstandards.org.uk/docs/default-
} 
average length of time for FTPP is 20 months from initial referral to decision, with some cases lasting over two years, with a common theme the time it takes for the HCPC to gather its evidence. ${ }^{102}$ During these lengthy waiting times registrants often cannot work and can face financial difficulties, a situation exacerbated for those without a working partner or spouse to support them during this time. The health consequences can be considerable. Of the eight respondents in the 'Interview' study, five revealed that they had either attempted suicide or had suicidal thoughts. ${ }^{103}$ Commonly, interviewees experienced prolonged distress which stemmed from a fear of failure and loss of professional identity. The fear of making another 'mistake' and being reported to the $\mathrm{HCPC}$ was a common theme and led to defensive techniques being implemented or to participants changing role completely. ${ }^{104}$ Many of the participants in the 'Interview' study talked of experiencing ongoing and debilitating stress that either left them feeling paranoid that this would happen again or meant they felt unable to return to social work. With the profession struggling to maintain morale and retain experienced practitioners, ${ }^{105}$ this is a major concern.

Two further points on the dignitarian element of the FTPP suggest that there is an embedded inequality of arms in the process, despite the HCPC's resources being entirely funded by registrant fees. First, in contrast to the registrant, the HCPC is always legally represented at the hearing. Second, whereas the process offers no financial and very little logistical support to the registrant, the HCPC's witnesses are funded to attend.

\section{Public Accountability}

\footnotetext{
source/publications/research-paper/public-response-to-alternatives-to-final-panel-hearings-2013.pdf?sfvrsn=6 (accessed 18 February 2018).

102 HCPC, n 62 above, 37.

103 Worsley et al n 3 above, 2433.

${ }^{104}$ Worsley et al $n 3$ above.

105 P McFadden, A Campbell and B Taylor 'Resilience and burnout in child protection social work: Individual and organisational themes from a systematic literature review' (2015) 45 British Journal of Social Work 1546.
} 
Multiple features of the court-like model, such as its transparency, objectivity and in-built appeal mechanism, provide for ways through which decisions can be publicly called to account, but to what extent do FTPPs integrate the values and operational pressures of the sector it oversees? The close connection between individual malpractice and organisational dysfunctionality was a theme that was highlighted in the 'Interview' study. In all eight interviews conducted, interviewees raised managerial concerns and experience of high complex caseloads. This connection can also be observed in the frequency with which referrals made by employers, made reference to organisational matters, such as recording, carrying out assessments or investigations, and following management instructions. The regularity in which such organisational issues are core to referrals was evident in a previous study by Furness, which carried out a content analysis of 265 social work conduct hearings held between 2006 and 31 July 2012. ${ }^{106}$ Additionally, in some cases registrants are self-referring themselves to the HCPC as a means to clear their names in ongoing disputes with their employers.

To explore the extent to which FTPPs considered the potential impact of organisational pressures on registrants, the 'Case Review' study deliberately selected cases in which it was the registrant's professional conduct, as opposed to personal conduct, that was under scrutiny. However, this study found that in only three out of 34 cases were organisational issues considered to any extent or impacted on the final decision. ${ }^{107}$

By way of example, Case 'I' involved allegations of misconduct due to 'deadlines being missed' and was supported by a letter from the registrant. ${ }^{108}$ The Panel found that she had only 'demonstrated limited acknowledgement of her failings' but accepted that the Children and Family Court Advisory and Support Service (CAFCASS), the referring organisation, were experiencing 'organisational changes'. These issues may have contributed to the registrant's

\footnotetext{
${ }^{106}$ S Furness 'Conduct Matters: The Regulation of Social Work in England' (2015) 45 British Journal of Social Work, 861, 870.

${ }^{107}$ Leigh et al, see $\mathrm{n} 3$ above.

${ }^{108}$ Ibid, 391.
} 
problems and subsequent resignation, as it became apparent in the hearing that her previous line manager, who had no issue with her practice before she went on sick leave, was also 'off sick'. The Panel decided only to issue a caution but there was no recommendation that the organisational issues should be explored any further. Similarly, in Case 'J' the Panel found competence issues 'understandable' because of problems emerging from the referring organisation. ${ }^{109}$ Nine allegations of misconduct were filed by the local authority against $\mathbf{J}$ (who had been a team manager) ranging from closing cases early, not responding to cases in a timely manner, allocating cases to a support worker instead of a social worker, fabricating case notes and other actions of dishonesty. Yet once the Panel heard evidence from the registrant, it decided to take no further action, accepting 'the Registrant's uncontroverted evidence' that problems occurred due to 'staffing shortages in her locality' and that the allegations emerged, in part, because of 'practices within the Council'. However, without a recommendation that the organisational problems should be investigated further, the likelihood is that such issues persisted and, in turn, affected other social workers employed there.

This low level concern with organisational matters, reflects the stated policy of the HCPC which is to retain a strict dividing line between regulatory and disciplinary perspectives even where organisational issues are raised, as its focus is on the individual professional. This approach can be contrasted with other regulatory processes in the sector, such as serious case inquiries which, whilst they provide a narrative and moral judgement about the conduct of professionals, also consider organisational factors that may have affected practice. ${ }^{110}$ Elsewhere, concerns have been raised that individual social workers could be held accountable for failings that are ultimately rooted in more systemic or organisational problems such as high caseloads, inadequate resources and poor staff supervision. ${ }^{111}$ This leads to an additional

\footnotetext{
${ }^{109}$ Ibid.

110 ibid.

${ }^{111}$ E Beddoe 'Surveillance or Reflection: Professional Supervision in the "Risk Society" ' (2010) 40(4) British Journal of Social Work 1279-1296.
} 
concern that sometimes providers might be using FTPPs to avoid organisational responsibilities towards managing underperforming staff, a practice alleged by participants in the 'Interview' study. Previous policy research has highlighted that social workers need to be in a supportive and enabling environment if they are to practise effectively. ${ }^{112}$ By contrast, FTPPs risk creating distrust because almost their entire focus is on the action and behaviour of the individual social worker, a focus which risks individualising and scapegoating the social worker whilst neglecting systemic issues.

\section{ALTERNATIVE DESIGN CHOICES}

\section{A thin procedural fairness regime}

Appropriately resourced FTPPs are capable of offering thick procedural fairness. In previous work, the court-like design of the FTPP has been described as facilitating a 'redemption model' of decision-making, through which the registrant is guided towards accepting the power of professional norms. Within this model, the goal of public protection is the main driver and outcomes are strongly influenced by whether or not registrants are willing to attend hearings and demonstrate a level of understanding and contrition. ${ }^{113}$ But although the model risks a 'contrived exchange' between the registrant and the FTPP, ${ }^{114}$ a strong dignitarian element of procedural fairness can be integrated. To achieve this outcome, however, participatory opportunities need to be institutionally supported to enable registrants either to defend their

\footnotetext{
${ }^{112}$ E Munro The Munro review of child protection: Final report - a child-centred system (London: Department for Education, 2011).

${ }^{113}$ Case, $\mathrm{n} 4$ above.

${ }^{114}$ Ibid, 591.
} 
actions or come to terms with their divergence from expected practice. Public accountability goals of procedural fairness can also be realised through FTPPs where the relevant sector retains a strong role in highlighting institutional failings and supporting its members. These latter roles are particularly powerful in the case of medicine for instance, in that the profession still has a key input into the development of the standards which are applied in FTPPs.

Notwithstanding the potential of FTPPs, the evidence compiled in this article indicates that for social workers the process provides a thin version of procedural fairness. The acknowledgment ritual that underpins the redemption model of FTPPs works best where the system proactively supports the registrant in terms of attendance, and through the advice of lawyers and the profession itself. By contrast, in the social work FTPP, the process provides a formal display of justice but achieves only a thin procedural fairness regime because the effective capacity of the sector to support the registrant is limited. This relationship structure is also, arguably, mirrored within the social work provider organisations where human resources departments are structured to support management performance on behalf of managers rather than employees. Additionally, for social workers, the voice and the perspective of the regulated sector has been much minimised through the imposition of lay regulation, combined with the financially and organisationally weak structure of the social worker profession. As a result, the achievement of the dignitarian and public accountability elements of procedural fairness are operationally weak in social work FTPPs. The arduous nature of the process leads to a large proportion of registrants being unable to participate meaningfully, or benefit from the in-built process of conciliation which operates for richer FTPPs. Further, there is an underlying tension with the social work FTPP in that it is unclear that social workers themselves have fully bought into the values that the process enforces, with a suspicion that it insufficiently recognises the 
organisational dynamics that influence instances of misconduct. Other studies have critiqued equivalent processes in other professions as convoluted, time consuming and expensive. ${ }^{115}$

The high public profile that has been attached to failings in child care regimes in recent years suggests that there will always be a demand for a strict 'court-like' model for social worker FTPPs. This dynamic has been in place since at least 1973, when social work was first linked to a child's death that was perceived to have been preventable, ${ }^{116}$ to more recent years when the detailed media reportage of the suffering of 'Baby P' had a profound impact on social, cultural and political group anxieties. As a result, social work practice has been dominated by continuous reform which has led to increasing bureaucratic and procedural approaches being implemented in the hope of eliminating uncertainty and risk. ${ }^{117}$

Nevertheless, there are policy pressures in the opposite direction. An inquiry into the State of Social Work identified that there is growing evidence of crisis in the profession as the current practice conditions present a notable challenge to social work morale and staff retention given the extreme stresses faced by both children's and adults' services. ${ }^{118}$ Coupled with the perception of unfairness surrounding the existing FTPP, these pressures may mean that alternative regulatory strategies become inevitable. Diverging strategies in professional regulation, including within FTPPs, is a known phenomenon. For instance, following a review of disciplinary decisions against doctors and solicitors, Case has demonstrated that the professional discipline process for doctors is more lenient with regard to dishonesty than that

\footnotetext{
115 See for example Health Committee 2013 accountability hearing with the Nursing and Midwifery Council HC699 (2013-14); Health Committee 2013 accountability hearing with the General Medical Council HC 897 (2013-14).

${ }^{116}$ I Butler and M Drakeford Social Work on Trial: The Colwell Inquiry and the State of Welfare (Bristol: Policy Press, 2011).

${ }^{117}$ J Warner “ "Heads Must Roll”? Emotional Politics, the Press and the Death of Baby P' (2013) 44(6) The British Journal of Social Work 1637.

${ }_{118}$ All Parliamentary Party Group Inquiry into the State of Social Work. (Birmingham: British Association of Social Workers, 2013) https://www.basw.co.uk/appg/ (accessed 4 February, 2018).
} 
for solicitors because of certain key factors pertaining to doctors. ${ }^{119}$ Plausibly this outcome reflects the value placed on respective professions and their relative dispensability. Socially, doctors are more trusted than solicitors and the public interest in retaining the services of a relatively scarce commodity, a fully trained doctor, weighs more heavily against the need to retain public confidence in the profession than the equivalent equation with solicitors. Regulatory design, therefore, is driven in part by responsive regulation strategies, ${ }^{120}$ in which by various means the needs of the sector help shape the manner in which regulation is implemented.

The need to respond proportionally to sector concerns in professional regulation has become a feature of recent Government consultations, ${ }^{121}$ but the key lies in matching the relevant environmental factors to the proposed model. ${ }^{122}$ The court-like model of professional discipline is expensive and is anachronistic in its inefficient formality in an era when civil and criminal justice reforms are innovating in new ways to introduce case management reform. Plausibly, to cover the likelihood of high numbers of referrals involving social workers, registrants could be required to take out insurance, but such a measure would only further shift the burden onto the professional. The introduction of a new regulator for social work, however, has provided a convenient opportunity to remodel the system for FTPP. ${ }^{123}$

\section{Adding a hybrid element to the fitness to practise process}

\footnotetext{
${ }^{119}$ P Case, 'Doctoring Confidence and Soliciting Trust: Models of Professional Discipline in Law and Medicine' (2013) 29 Professional Negligence 87. See also J. Chamberlain, 'Doctoring with conviction: criminal records and the medical profession.' The British Journal of Criminology (forthcoming).

${ }^{120}$ I Ayres and J Braithwaite Responsive Regulation: Transcending the Deregulation Debate (Oxford: OUP, 1992).

${ }^{121}$ Department of Health, Promoting professionalism, reforming regulation: a paper for consultation (Leeds: DoH, 2017).

122 O Kahn-Freund 'On the uses and misuses of comparative law' (1974) 37(1) MLR 1.

${ }^{123}$ Department of Education and Department of Health and Social Care, $\mathrm{n} 5$ above.
} 
One alternative is to reconsider the court-like rigidity of the existing FTPP by shortening the process and reducing the occurrence of hearings. Recognising the potential for many of the concerns raised in this article, previously the Government has accepted that wider regulatory goals are not best promoted by a monolithic approach to handling fitness to practise issues. ${ }^{124}$ Until very recently though, there has been a reluctance to think imaginatively about how this process could be reformed, with considerations of public protection paramount.

Of the alternative models available, the adoption of a mediation focused process has already been raised as a possibility and rejected. ${ }^{125}$ However, in a recent consultation paper, the Government has proposed shifting towards an early resolution model, whereby 'accepted disposal' of cases with registrant consent is facilitated through the recommendation of 'case examiners' upon receipt of reports by 'investigators' ${ }^{126}$ If put in place, what we will see in the design of the social work FTPP is a more 'hybrid' structure of dispute resolution which is novel to the FTPP sector and more in line with that operated within some parts of the ombudsman sector, such as the Scottish Legal Complaint Commission (SLCC).

The SLCC does not deal with conduct proceedings against legal professions, as these are transferred to a standard 'court-like' FTPP model managed by a separate professional body. ${ }^{127}$ Nevertheless, although a form of ombudsman which deals with service complaints only, the SLCC operates in a more structured fashion than standard complaints processes making it an interesting example of a hybrid model of dispute resolution which could be replicated for fitness to practise matters in a profession such as social workers.

\footnotetext{
${ }^{124}$ Department of Health, see n 35 above, para 5.8 and Law Commission, Scottish Law Commission, Northern Ireland Law Commission. Regulation of Health Care Professionals. Regulation of Social Care Professionals. Cm. 8839 (London: TSO, 2014), 131-4.

${ }^{125}$ Department of Health, see n 35 above, para.5.27.

${ }^{126}$ Draft Social Workers Regulation 2018, cl 26 and Sched 3 available at: https://consult.education.gov.uk/socialwork-england-implementation-team/social-work-england-consultation-on-secondarylegi/supporting documents/Proposed\%20Social\%20Workers\%20regulations.pdf (accessed 22 February 2018).

${ }^{127}$ Either the Law Society for Scotland or the Faculty of Advocates.
} 
The SLCC process involves five layers of decision-making, with each layer taking on a more court-like hue. ${ }^{128}$ At the first layer, complaints are received and eligibility issues considered, with complaints transferred out of the system to a relevant professional body if the SLCC classify it as a conduct complaint. ${ }^{129}$ The second and third stages of the SLCC model embeds a mediation stage and then an investigation stage within its operation, both of which are designed to facilitate an early agreed settlement of a dispute if possible and appropriate. The fourth stage in its process is a formal determination of the matter before an independent panel if either party to the dispute reject the SLCC's findings or recommendations. Here the SLCC model differs from most ombudsman schemes, in that not only is a formal panel allowed for but the decision of the determination panel is final, subject to the option to move to a fifth stage, a judicial appeal.

In mimicking elements of this hybrid model of dispute resolution for social work FTPPs, the key innovation is the third stage, in which the investigation is used to settle the matter before a hearing even if the registrant is found to have breached standards and even if a sanction is being recommended. The standard objection to this solution is that it is contrary to ordinary expectations of procedural fairness in disciplinary processes for sanctions to be made without a hearing. But the Government's proposals recognise that procedural fairness is a fluid concept, which allows decision-making processes to be designed proportionally to the context in which they operate.

In this sense, and viewed through the tripartite elements of procedural fairness adopted in this article, the model looks promising, subject to some significant qualifications.

\footnotetext{
${ }^{128}$ Scottish Legal Complaints Commission, Overview of the process for dealing with service and conduct complaints available at: https://www.scottishlegalcomplaints.org.uk/making-a-complaint/complaintsprocess.aspx (accessed 18 February 2018).

${ }^{129}$ Following the decision in Anderson Strathern Llp v The Scottish Legal Complaints Commission [2016] ScotCS CSIH_71, [23-29], it is no longer lawful for a complaint to be treated as a 'hybrid complaint' ie investigated both by the SLCC (for service matters) and a professional body (for conduct matters).
} 
Is the hybrid model instrumentally fair?

Instrumentally, the goal is to reduce the number of panel hearings, cost and time in the processing of fitness to practise allegations, whilst retaining the veneer of rigour in terms of public protection. ${ }^{130} \mathrm{~A}$ key concern here, however, is minimising the risk of incorrect outcomes as a result of the non-use of hearings. On this, five points in favour of the solution can be noted.

First, given that currently decisions at the hearing stage are largely driven by a registrant's capacity to attend and willingness to express contrition, it is unclear that the registrant would be disadvantaged by at an earlier stage choosing to forgo a hearing in circumstances where there is a lack of support structure to help him/her take advantage of that opportunity.

Second, for less serious sanctions the requirement for the consent of the registrant could be sufficient provided offsetting safeguards were in place. Indeed, the Law Commission has previously concluded that the court-like model need not always be followed for FTPPs. ${ }^{131}$ Under Article 6 of the European Convention of Human Rights access to a tribunal is required in certain circumstances where a civil right is in play. If an individual has a legal expectation of registration then their position on the register can be considered to represent a civil right, the removal of which requires the authority of a tribunal. Further, the case law suggests that a limited right to appeal or review to the higher courts should be made available in such circumstances. ${ }^{132}$ But this body of law does not necessitate that all fitness to practise matters need to be dealt with through a tribunal. Where the sanctions being imposed amount to conditions of practise only, it is doubtful that Article 6 obligations apply at all, ${ }^{133}$ and with the common law on natural justice the correct process is dependent on the context of the dispute

\footnotetext{
${ }^{130}$ Department of Education and Department of Health and Social Care, $\mathrm{n} 7$ above.

${ }^{131}$ Law Commission, n 124 above, ch.8.

${ }^{132} \mathrm{Eg} R$ (Royal College of Nursing) v Secretary of State for the Home Department [2010] EWHC 2761 (Admin), [2011] 2 FLR 1399 at [92];

${ }^{133} \mathrm{Eg} R$ (Nicolaides) v General Medical Council [2001] EWHC Admin 625, [2001] Lloyd's Rep. Med. 525 at [28] to [32]. This was also the view of the Law Commission, see n 124 above, para 8.39.
} 
being considered. ${ }^{134}$ Given this analysis, however, an area of the current proposals that needs to be reconsidered is the proposal that a registrant could be removed from the register by the 'accepted disposal' process. ${ }^{135}$

Third, the hybrid process being proposed for the social work FTPP builds in an additional safeguard by separating out the functions of investigation and determination. Thus on completion of the investigation, the investigator passes on their report to "two or more case examiners ${ }^{136}$ who are then responsible for recommending closure of the case by way of 'accepted disposal'. ${ }^{137}$ Bolstered by this separation, compared to the present situation, the determinations made by the case examiners could be much more selective in identifying those cases where a breach of standards has occurred but for which a less serious sanction is sufficient and can be delivered through the 'accepted disposal' process.

Fourth, case examiners would not have the final say in closing an investigated referral. Thus, not only would it be a pre-requisite for the registrant to consent to any sanction imposed, the registrant will have a right to request a formal determination of their referral ie a hearing. ${ }^{138}$

Finally, a further safeguard against inadequate procedural fairness already exists within the standard FTPP model. The process is buttressed by the role of another body, the Professional Standards Authority for Health and Social Care, which reviews all final decisions made by the regulators on fitness to practise and can challenge decisions should it view its findings as unduly lenient.

Does the hybrid model enhance dignitarian and public accountability models of fairness?

\footnotetext{
${ }^{134}$ Doody, n 36 above.

${ }^{135}$ A particular problem is the ability of case examiners to impose interim orders suspending registrants from practicing, L Stevenson 'New fitness to practise process could threaten social workers' human rights, professional body warns' (22 February, 2018) Community Care available at: http://www.communitycare.co.uk/2018/02/22/new-fitness-practise-process-threaten-social-workers-humanrights-professional-body-warns/ (accessed 22 February 2018).

${ }^{136}$ Draft Social Workers Regulation 2018, Sched 3, Art 3.

${ }^{137}$ Ibid, Sched 3, Art 13-15.

${ }^{138}$ Ibid, Sched 3, Art 16.
} 
The research that supports this study has identified that the current operation of the social work FTPP process inadequately integrates the registrant's voice or factors in all relevant institutional factors. To get around these barriers, placing the enhanced onus on inquisitorial methods may offer a very appropriate methodology of dispute resolution for the social work sector. The distinct difference that gives cause for optimism in the hybrid design as operated by a body such as the SLCC and other ombudsman schemes is that, more than a strict court-like process, an inquisitorial process offers the potential for decision-makers to be more proactive and innovative in the methods deployed to investigate and resolve a complaint. Much work may still be based on paper submissions but, as is appropriate, telephone calls, internet conferences and site visits are a feature of the ombudsman model and could be more readily applied to the FTPP process. A further encouraging feature of inquisitorial ombudsman processes is the capacity to use the dispute resolution process to identify system failings in organisations that might have underpinned isolated instances of error. The objective, in other words, goes beyond remedying the individual complaint and looks to enhance organisational accountability.

Hybrid models of decision-making therefore offer rich potential for procedural fairness. However, hybrid models such as the ombudsman do not uniformly achieve procedural justice in the eyes of the user. ${ }^{139}$ The inference is that positive outcomes in dignitarian and public accountability terms cannot be guaranteed and require planned investment. As currently drafted, the proposed new social work FTPP seems quite an oppressive model, one designed to help the regulator streamline the decision-making process rather than assist the social worker. This may benefit the social worker in terms of shortening the pain of being subject to fitness to practise proceedings, but so long as the process remains paper-based and there is no

\footnotetext{
${ }^{139} \mathrm{~N}$ Creutzfeldt and B Bradford 'Dispute resolution outside of courts: procedural justice and decision acceptance among users of ombuds services in the UK' (2016) 50(4) Law and Society Review 985.
} 
commitment to support registrants more proactively through the process then the gains in thicker procedural fairness terms will be minimal. Further, unless an enhanced willingness to engage in institutional shortcomings is integrated into the process, then the concerns of the profession about being blamed for both the contextual and organisational challenges of social work will continue to undermine morale.

\section{CONCLUSION}

This article has questioned the merits of the blanket transposition of 'court-like' models of FTPPs to all professions, through an exploration of the concept of procedural fairness and one particular profession, social work. Demands for procedural fairness are usually seen to require 'court-like' processes where career threatening sanctions are at stake, but this article has argued that procedural fairness is a context dependent concept, and FTPP design should be sensitive to its environmental context. Further, without the financial and institutional support structures to safeguard the interests of the registrant and the profession, the blanket application of the "courtlike' FTPP represents a thin provision of procedural fairness that risks undermining the longterm integrity of the process.

This article has additionally argued that if we are to take the broader goals of procedural fairness seriously in contexts such as social work, then subtle revisions to the FTPP design should be contemplated to support registrants and enhance the connectivity of the FTPP with the social work profession. Current Government policy is to place a greater emphasis upon the inquisitorial work conducted at the pre-hearing stages in order to settle sanctions through the voluntarily cooperation of the registrant and reduce the need for full hearings. The major objection against such a solution is the fundamental need to retain public confidence in the level 
of public protection being provided for. But here gains could be achieved through an enhanced willingness of professional regulators to use FTPPs to highlight institutional failings that give rise to individual failings. The concern must be, however, that absent of an investment in working with investigated registrants and a renewed focus on learning institutional lessons from FTPP cases, the social work FTPP will continue to offer only thin procedural fairness. 